\title{
Fast bioremediation of petroleum-contaminated soils by a consortium of biosurfactant/bioemulsifier producing bacteria
}

\author{
R. Barin · M. Talebi · D. Biria $\cdot$ M. Beheshti
}

Received: 4 October 2013/Revised: 7 February 2014/Accepted: 21 April 2014/Published online: 6 May 2014

(C) Islamic Azad University (IAU) 2014

\begin{abstract}
Biodegradation of petroleum hydrocarbons as a decontamination mechanism is a relatively slow process. This study aimed to investigate the impact of a tailored consortium of bacteria with higher capacities in biosurfactant production and biodegradation on the acceleration of the biodecontamination process. To this end, 18 biosurfactant producing bacteria were isolated from the crude oil-contaminated soil samples of Isfahan refinery, and the activity of the produced biosurfactants was measured in terms of surface tension reduction and emulsification E24 test. Then, the isolates screened for the biodegradation of kerosene hydrocarbons and chemical structure of the purified biosurfactants produced by the most efficient isolates were partially characterized. Next, the isolates were sorted based on their surfactant activity and biodegradation efficiency, and the higher ranked bacteria thus selected were utilized to form an efficient consortium removing hydrocarbons from the oil-contaminated soil samples in a slurry phase system. The consortium consisted of Bacillus subtilis tb1 and Pseudomonas aeruginosa species having the highest biodegradation capabilities and surface activities. The results revealed that the hydrocarbon removal efficiency of the consortium was at least $25 \%$ higher than single species, and the final removal efficiency for the consortium could be reached in a considerably shorter time.
\end{abstract}

R. Barin · M. Talebi · D. Biria $(\bowtie)$

Department of Biotechnology, Faculty of Advanced Sciences and Technologies, University of Isfahan, Hezar Jarib Ave., Isfahan, Iran

e-mail: d.biria@ast.ui.ac.ir

M. Beheshti

Chemical Engineering Department, Faculty of Engineering, University of Isfahan, Hezar Jarib Ave., Isfahan, Iran
Keywords Fast bioremediation - Bacterial consortium · Biosurfactant $\cdot$ Bioemulsifier $\cdot$ Hydrocarbon

\section{Introduction}

The extensive consumption of petroleum hydrocarbons as a major energy source and an important feedstock to chemical industries has increased concerns about oil contamination and its harmful environmental consequences all over the world. Accordingly, several technologies have been developed to address the problem and satisfy the strict environmental regulations. Among them, bioremediation is one of the most promising techniques which has certain inherent merits (e.g., low costs, in situ treatment capability and environmental friendly nature) over other physical or chemical based processes (Das and Chandran 2011; Rayu et al. 2012).

This technology involves the removal of petroleum hydrocarbons from the contaminated site by the act of microorganisms in a complex multi-phase system. Consequently, the efficiency of the process, it may be said, depends strongly on the ability of microorganisms in degrading hydrocarbons effectively. As such, the isolation of potentially applicable microorganisms to bioremediation of a variety of oily contaminations has received a lot of ink in the related literature (Watanabe 2001; Ruggeri et al. 2009; Vasconcellos et al. 2009; Mbadinga et al. 2011). However, the main drawback of bioremediation processes in a majority of cases is the slow biodegradation rate of hydrocarbons (Kumar et al. 2011). The problem is even more serious, especially in economical terms, when the process would be performed in a reactor or a vessel such as that of slurry phase reactor bioremediation. 
Supposedly, the main culprit in the low degradation rate is related to the existing limitations in hydrocarbon mass transfer to microorganisms in the aqueous phase because of the low solubility of hydrocarbons in water (Mulligan et al. 2001; Calvo et al. 2009, Biria et al. 2013). In fact, the main mechanism for transporting hydrocarbons to microbial cells is the attachment of these cells to oil-water interface and the diffusion of the hydrocarbons into the cells (Abbasnezhad et al. 2008). Consequently, the application of surfactants to disperse oily phase in the form of emulsion droplets in aqueous medium is suggested to increase bioavailability of hydrocarbons and enhance the rate of biodegradation (Bordoloi and Konwar 2009).

It is frequently reported that various types of microorganisms can produce "biosurfactants," and this capability is often intensified with their growth on nearly insoluble hydrocarbons as the sole carbon source (Ron and Rosenberg 2002). In many cases, biosurfactants have certain advantages over their chemical counterparts (i.e., lower toxicity, biodegradability and higher activity at extreme conditions) turning them into a potentially effective agent to be used in bioremediation processes (Makkar and Rockne 2003). Unfortunately, the amounts of secreted biosurfactant in the system might be insufficient to influence the bioavailability of hydrocarbons significantly (Mukherjee et al. 2006). Moreover, biodegradation and biosurfactant production capabilities of microorganisms are related to the formulation of the culturing media, and sometimes, these capabilities are not present simultaneously in a single species. Therefore, the application of a consortium of microorganisms to remove petroleum contaminations in a bioremediation process is highly recommended (Rahman et al. 2002; Ghazali et al. 2004; GojgicCvijovic et al. 2012). In fact, the consortium includes microorganisms with a high ability in biodegradation of various types of hydrocarbons as well as those which can produce biosurfactants effectively. Furthermore, the verdict about the potential capabilities of a single isolate in a bioremediation process should not be considered independently from the whole biosystem. In the present work, an attempt was made to study the impact of the biosurfactant producing species in a bacterial consortium on the hydrocarbons biodegradation rate. The research has been performed in the laboratories of Department of Biotechnology, University of Isfahan at 2012 and 2013.

\section{Materials and methods}

Microorganisms and culturing media

To obtain potentially effective microorganisms applicable to an effective bioremediation process, five $\mathrm{g}$ of an oil- contaminated soil sample taken from Isfahan petroleum refinery was added to 250-ml Erlenmeyers flask containing $50 \mathrm{ml}$ of Bushnell-Hass medium. Flasks were incubated at $37{ }^{\circ} \mathrm{C}$ for 10 days. After the incubation period, single colonies of microorganisms were purified on nutrient agar plates by streaking. Then, morphological and physiological characteristics of the obtained species were studied, and the isolates were screened on the basis of their capability in kerosene hydrocarbons biodegradation or biosurfactant/ bioemulsifier production. DNA was extracted for the amplification of the 16S-rRNA gene by the boiling lysis method (Ko et al. 2006). The 16S-rRNA genes were amplified using RW01 (5'-AAC TGG AGG AAG GTG GGG AT- $\left.3^{\prime}\right)$ and DG74 (5'-AGG AGGTGA TCC AAC CGC A-3') universal primers.

\section{Biosurfactant production and characterization}

Each distinct isolate was inoculated in $50 \mathrm{ml}$ of BushnellHass medium supplemented with $1 \%(\mathrm{v} / \mathrm{v})$ kerosene in a 250-ml Erlenmeyer flask and was incubated for 4 days at $37^{\circ} \mathrm{C}$ and $180 \mathrm{rpm}$. After incubation, the bacterial cells were harvested by centrifugation $(10,000 \times g, 10 \mathrm{~min})$. The resultant supernatants were screened for biosurfactant production by oil spreading method as described by Noha et al. (2004). Biosurfactant positive samples (raw biosurfactant solutions) were submitted to surface activity measurements. Surface tension values were determined with a duNouy ring tensiometer (K20, Kruss, Germany), at the ambient temperature $\left(23{ }^{\circ} \mathrm{C}\right)$ for at least three times. The control was a sample of culturing medium without any bacterial inoculation. The reported values formed the mean values of repeated measurements. Emulsification capability of the samples was determined by calculating E24 index (Abouseoud et al. 2008). Two $\mathrm{ml}$ of kerosene were added to the same volume of the centrifuged broth and were subsequently vortexed for $2 \mathrm{~min}$. The obtained mixture was left to stand for $24 \mathrm{~h}$. The E24 index was given as the height of emulsified layer $(\mathrm{mm})$ divided by total height of the liquid column (mm) in percents. Only those biosurfactant samples with the highest tensio-active properties were screened for further analysis.

\section{Biosurfactant purification and partial characterization}

The presence of carbohydrates in the biosurfactant molecule was assayed by rhamnose test using the phenol-sulfuric acid method and glucose as standard (Dubois et al. 1956). A volume of $0.5 \mathrm{ml}$ raw biosurfactant solution was mixed with $0.5 \mathrm{ml}$ of $5 \%$ phenol solution and $2.5 \mathrm{ml}$ of sulfuric acid. The absorbance of the mixture was measured at $490 \mathrm{~nm}$ after $15 \mathrm{~min}$. The presence of peptide groups in the biosurfactant molecules was assayed by Lowry test 
(Lowry et al. 1951). Bovine serum albumin was utilized to produce the standard curve, and the absorbance of the sample was measured at $650 \mathrm{~nm}$.

Acid precipitation followed by solvent extraction was utilized to isolate biosurfactants. Raw biosurfactant solution samples were acidified by a $6 \mathrm{~N} \mathrm{HCl}$ solution to reduce $\mathrm{pH}$ to two and stored at $4{ }^{\circ} \mathrm{C}$ for $24 \mathrm{~h}$. Precipitates were collected by centrifugation (22,000 rpm, $10 \mathrm{~min})$ and were dissolved in a $0.05 \mathrm{M} \mathrm{Na}_{2} \mathrm{CO}_{3}$ solution $(\mathrm{pH}=8.6)$. Subsequently, another round of acid precipitation was applied to this solution before solvent extraction. The obtained precipitates were suspended in a solvent phase consisting chloroform and ethanol (2:1 ratio) and were vigorously mixed. The supernatant containing biosurfactant molecules was separated by centrifuge $(15,000 \mathrm{rpm}, 10 \mathrm{~min})$ and vacuum dried by a rotary evaporator. The obtained dried powder was washed by ethanol to remove colored pigments and impurities. The chemical structure of the purified biosurfactants was partially determined by infrared (IR) spectroscopy (JASCO, FTIR-6300, Japan).

\section{Biodegradation of kerosene}

The capability of the isolates in hydrocarbons assimilation was also investigated through kerosene biodegradation. Kerosene was selected as the model oil because it contains a wide variety of hydrocarbons including straight and branched paraffins, naphthenics and aromatic components such as alkyl benzenes and naphthalene and its derivatives. Flasks containing $100 \mathrm{ml}$ of $\mathrm{BH}$ mineral medium were supplied with $1 \%(\mathrm{~V} / \mathrm{V})$ kerosene as the sole carbon source. Then, $2 \mathrm{ml}$ of a culture containing $10^{8}$ cells per $\mathrm{ml}$ added to the solution. One of the flasks was left without any inoculations as the blank. Finally, the obtained broths were incubated in an orbital shaker $\left(180 \mathrm{rpm}, 37^{\circ} \mathrm{C}\right)$ for 4 days. The amounts of hydrocarbon uptake by the cells were measured by a procedure suggested by Palittapongarnpim et al. (1998). Biomass was separated from the broth by centrifuging (Sigma 3k30, UK) at 10,000 rpm for $20 \mathrm{~min}$. Hydrocarbons were extracted from the supernatant by $20 \mathrm{ml}$ chloroform, and the extract was separated from the aqueous phase using a decanter funnel. Residual water content of the extract was eliminated by passing it through ammonium sulfate layer placed on a paper filter (Wattman Number 4). Finally, hydrocarbon content of the extract was measured by gas chromatography (Agilent Technologies $6890 \mathrm{~N}$, USA) equipped with a HP5 capillary column and a FID detector. Injector and detector temperatures were set to 280 and $300{ }^{\circ} \mathrm{C}$, respectively. The oven temperature was set to $100{ }^{\circ} \mathrm{C}$ for $1 \mathrm{~min}$ and then increased to $210{ }^{\circ} \mathrm{C}$ by $15^{\circ} \mathrm{C} / \mathrm{min}$ slope and kept constant for $3 \mathrm{~min}$. Helium was used as the carrier gas at a flow rate of $2 \mathrm{ml} / \mathrm{min}$. The retention times of the pure hydrocarbons, including $n-C 10$, $\mathrm{n}-\mathrm{C} 12$ and $\mathrm{n}-\mathrm{C} 15$, were equal to $5.5,8.4$ and $11.57 \mathrm{~min}$, respectively.

Application of consortium to bioremediation of the crude oil-contaminated soils

The most active species in biodegradation and biosurfactant production was selected to participate in the consortium which was attained by mixing equal proportions of each strain in $\mathrm{BH}$ mineral medium. To compare the efficiency of the selected consortium with that of the highest active single isolates (no. 1 and 3), total petroleum hydrocarbon removal efficiencies of both systems were measured for synthetic crude oil-contaminated soil samples in 5 days under indoor laboratory conditions. First, soil samples were screened (mesh size no. 200), washed out with n-hexane and then dried in oven to remove any traces of organic contaminations. Subsequently, oil-contaminated samples were prepared by adding $8 \%$ (W/W) filtered crude oil to the obtained clean soil and stored for 1 week at the room temperature. $150 \mathrm{~g}$ of the contaminated soil was added to $500 \mathrm{ml}$ of the sterilized $\mathrm{BH}$ medium in a 2-1 glass vessel and mixed firmly. The slurry was inoculated by $5 \mathrm{ml}$ of a bacterial suspension containing a total count of $10^{9}$ cell $/ \mathrm{ml}$. A blank test with no inoculation was also prepared to control the non biological effects. The slurry phase reactors were placed on a jar test apparatus and stirred continuously for 5 days at $280 \mathrm{rpm}$ and at the room temperature. They were then allowed to settle for $2 \mathrm{~h}$, and the supernatant poured off. The total petroleum hydrocarbon (TPH) content of the soil samples was determined by soxhelet chloroform extraction (EPA Method SW-846 3540). The hydrocarbon removal efficiency was calculated as the normalized difference between the soil sample and the blank test TPH. To ensure the reproducibility of the results, all tests were performed in duplicates.

\section{Results and discussion}

Isolation and screening of microorganisms

Eighteen different colonies of bacteria were isolated from hydrocarbon-contaminated soil samples. Results of the biochemical tests and morphological characterization have 
been shown in Table 1. Oil spreading test revealed that all of the isolates were biosurfactant producing species although the activity of the produced biosurfactants was not the same. The obtained values of the surface tension measurements as well as the emulsification index (E24) have been shown in Fig. 1. Results showed that the produced biosurfactant by strain no. 13 has the minimum surface tension value $(30 \mathrm{mN} / \mathrm{m})$, and the maximum emulsification capability was measured for the strain no. 10. Accordingly, the most tensio-active strains were number 1, 3, 6, 10 and 13 . The $370 \mathrm{bp}$ of 16S-rDNA gene of these strains was deposited in GenBank under the accession numbers KC309409, JX163115, KC309410, KC309412 and KC309413, respectively. Alignment of the sequences with described species showed more than $99 \%$ similarity to Bacillus subtilis for number 1 and to Pseudomonas aeruginosa for the other strains. The assigned name for each species has been listed in Table 1 .

Biosurfactant purification and partial characterization

Results of the rhamnose tests indicated that the biosurfactants produced by the strains identified as pseudomonas species had a glycolipid nature while the bacillus

Table 1 Results of the biochemical tests and morphological characterization of the isolates

\begin{tabular}{|c|c|c|c|c|c|c|c|c|}
\hline No. & Morphology & Gram reaction & Motility & Catalase & MR & VP & Indole & Assigned name \\
\hline 1 & Bacilli & $\mathrm{G}+$ & + & + & - & + & - & Bacillus subtilis TB1 \\
\hline 2 & Cocci & $\mathrm{G}+$ & + & - & - & + & - & \\
\hline 3 & Bacilli & $\mathrm{G}-$ & + & + & + & - & + & Pseudomonas aeruginosa TB3 \\
\hline 4 & Bacilli & $\mathrm{G}+$ & - & - & + & - & - & \\
\hline 5 & Bacilli & $\mathrm{G}+$ & + & - & - & + & - & \\
\hline 6 & Bacilli & $\mathrm{G}+$ & + & + & + & - & + & Pseudomonas aeruginosa TB6 \\
\hline 7 & Coccobacilli & $\mathrm{G}+$ & + & - & + & - & - & \\
\hline 8 & Coccobacilli & $\mathrm{G}-$ & + & + & + & - & - & \\
\hline 9 & Coccobacilli & $\mathrm{G}-$ & + & + & + & - & + & \\
\hline 10 & Cocci & $\mathrm{G}+$ & + & + & + & - & - & Pseudomonas aeruginosa TB10 \\
\hline 11 & Coccobacilli & $\mathrm{G}+$ & - & + & - & + & - & \\
\hline 12 & Coccobacilli & $\mathrm{G}-$ & + & + & + & - & - & \\
\hline 13 & Bacilli & $\mathrm{G}-$ & + & + & + & - & - & Pseudomonas aeruginosa TB13 \\
\hline 14 & Coccobacilli & $\mathrm{G}-$ & - & + & + & - & - & \\
\hline 15 & Bacilli & $\mathrm{G}-$ & + & + & - & + & - & \\
\hline 16 & Cocci & $\mathrm{G}+$ & + & + & + & - & + & \\
\hline 17 & Coccobacilli & $\mathrm{G}+$ & + & - & + & - & - & \\
\hline 18 & Bacilli & $\mathrm{G}-$ & + & + & + & - & - & \\
\hline
\end{tabular}

Fig. 1 Surface tension and emulsification index (E24) values of the isolates

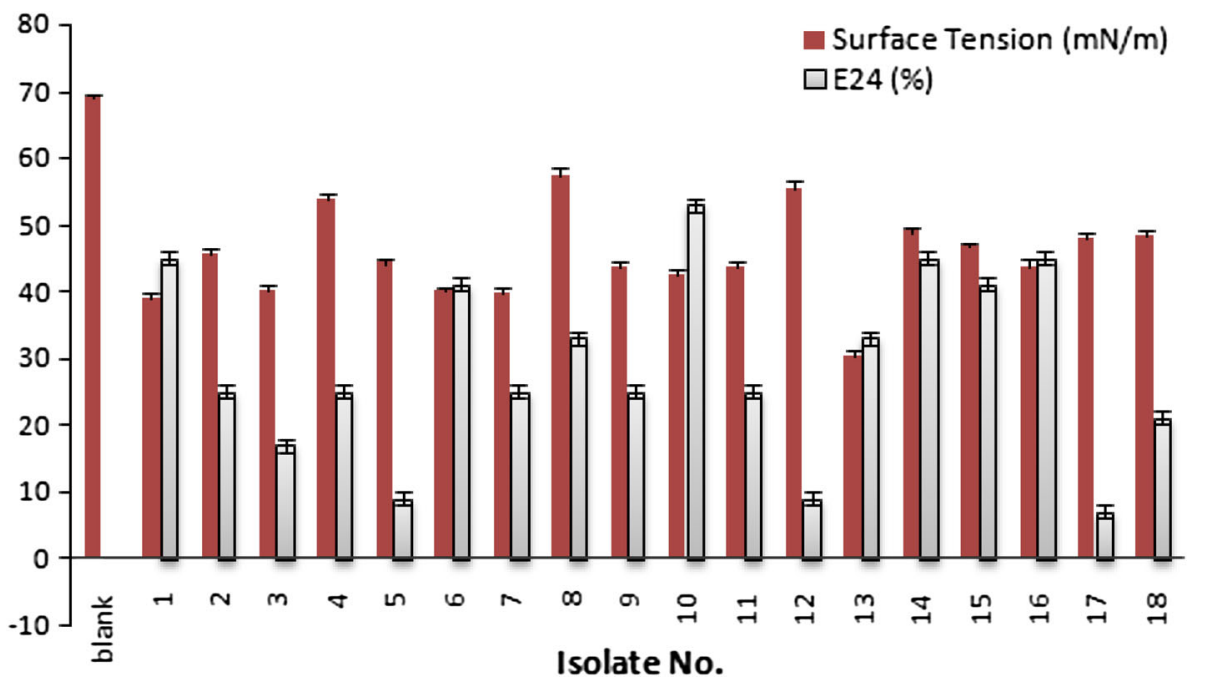



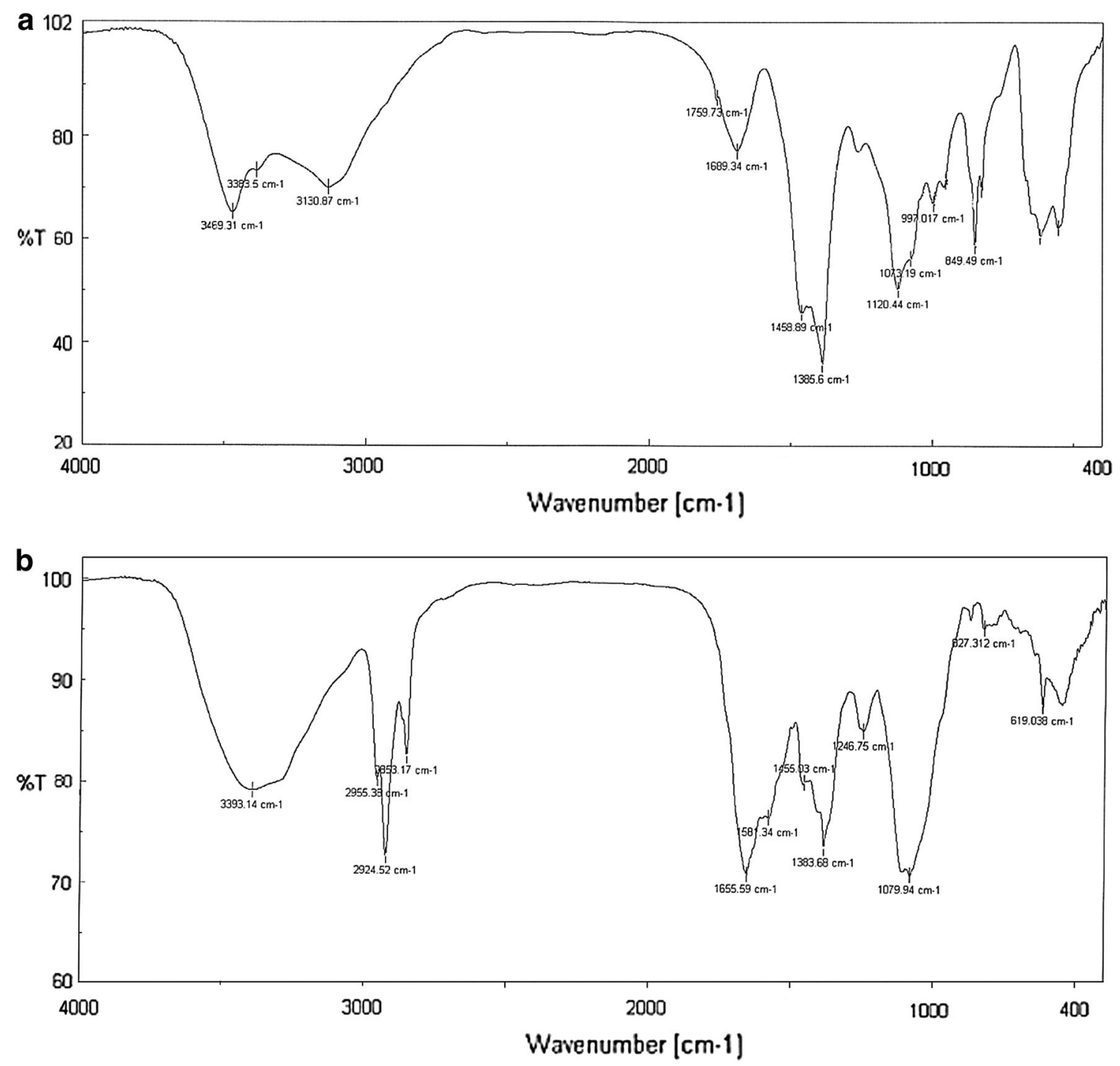

Fig. 2 IR spectrum for the biosurfactant of Bacillus Subtilis tb1 (a) and for the biosurfactant produced by the Pseudomonas aeruginosa tb13 (b)

biosurfactant showed to have a peptide section in its structure. It is frequently reported that the chemical structure of the pseudomonas biosurfactants consists of a carbohydrate moiety bonded to a fatty acid through a carbonyl ester bond (Soberón-Chávez et al. 2005). The IR spectra of the purified biosurfactants of strains 1 and 13 have been shown in Fig. 2. The IR results for other pseudomonas strains representing glycolipid biosurfactants were almost similar to no. 13 with minor variations. Figure 2a shows the IR for the biosurfactant of Bacillus Subtilis tb1 which seems to be a lipopeptide because of the peptide bonds characteristics appeared in the spectrum (wave numbers 1,689 for $\mathrm{CO}, 1,120$ for $\mathrm{CN}$ and 3,383 and 3,469 for amine groups). Other Peaks around 1,458 and 1,385 are related to the aliphatic groups in the lipid tail of the molecule. Figure $2 b$ represents the functional groups of the biosurfactant produced by the Pseudomonas aeruginosa tb13 which are assumed to belong to rhamnolipid biosurfactants. The rationale behind this conclusion is the wide peak around 3,396 which is representative for hydroxyl groups because it has been accompanied by a peak at 1,655 ester carbonyl group. Aliphatic components of the lipid moiety are visualized by the peaks at 2,955 , $2,925,2,853$ and 1,383 . 


\section{Biodegradation of kerosene}

Figure 3 shows the amounts of kerosene degraded by the isolates after 4 days. The maximum biodegradation belonged to isolates no. 1 and no. 10. Apparently, the isolates with more active biosurfactants (high emulsification capability and surface tension reduction) were more effective in biodegradation of kerosene hydrocarbons. A biosurfactant with high activity in terms of surface tension reduction decreases the required energy for the formation of emulsion droplets through lowering the interfacial energy barrier between the two immiscible phases. However, the arrangement of the biosurfactant molecules at the interface reduces the entropy of the system which adversely affects the dispersion of two phases in the form of emulsions. In this case, energy should be utilized (e.g., by agitation) to neutralize the undesirable entropy effect, and the produced emulsion would be decomposed with time. On the other hand, a biosurfactant with high emulsification capability (bioemulsifier) might not be very effective in reduction of the energy of emulsion formation, but as an emulsion formed in the system it can stabilize the structure through molecular interactions (e.g., strong hydrophobic interactions of tail segments of the molecules or hydrogen bonds in the head part of the molecule) in such a way that the negative influence of the entropy would be completely covered. Figure 4 demonstrates the details of the concept graphically. As a result, when there were a balance between the surface tension reduction and emulsification capabilities, smaller and more stable emulsions

Fig. 3 The amounts of kerosene hydrocarbons degraded by the isolates after 4 days
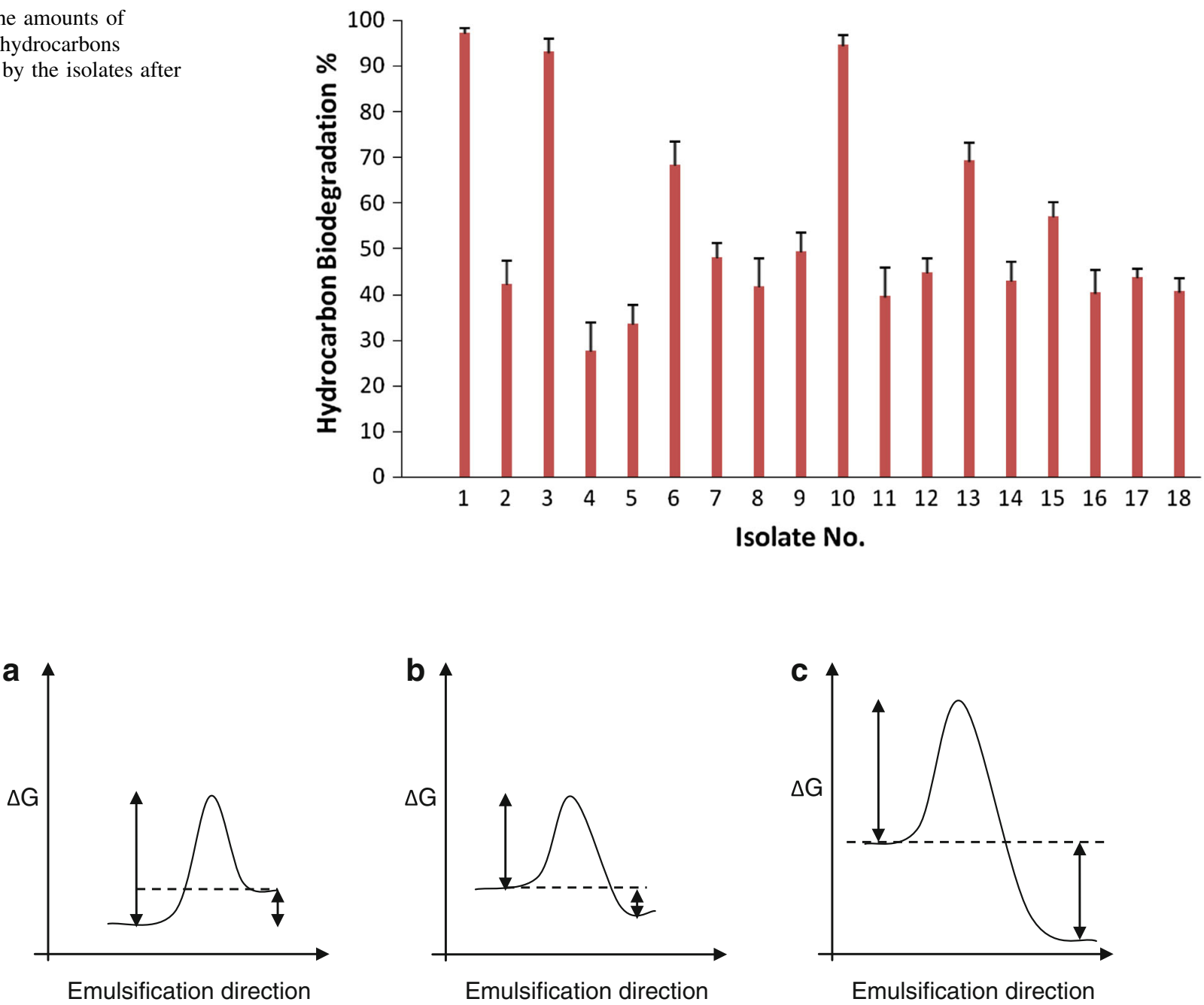

Fig. 4 Free energy change of biosurfactant containing systems in an emulsification process: a biosurfactant with high capability in surface tension reduction under critical micelle concentration (a) more than critical micelle concentration (b), a biosurfactant with high emulsification index $(\mathbf{c})$ 
Fig. 5 The hydrocarbon removal from the oilcontaminated soil sample by the consortium in comparison with Bacillus Subtilis tb1 and Pseudomonas aeruginosa tb10 in terms of TPH

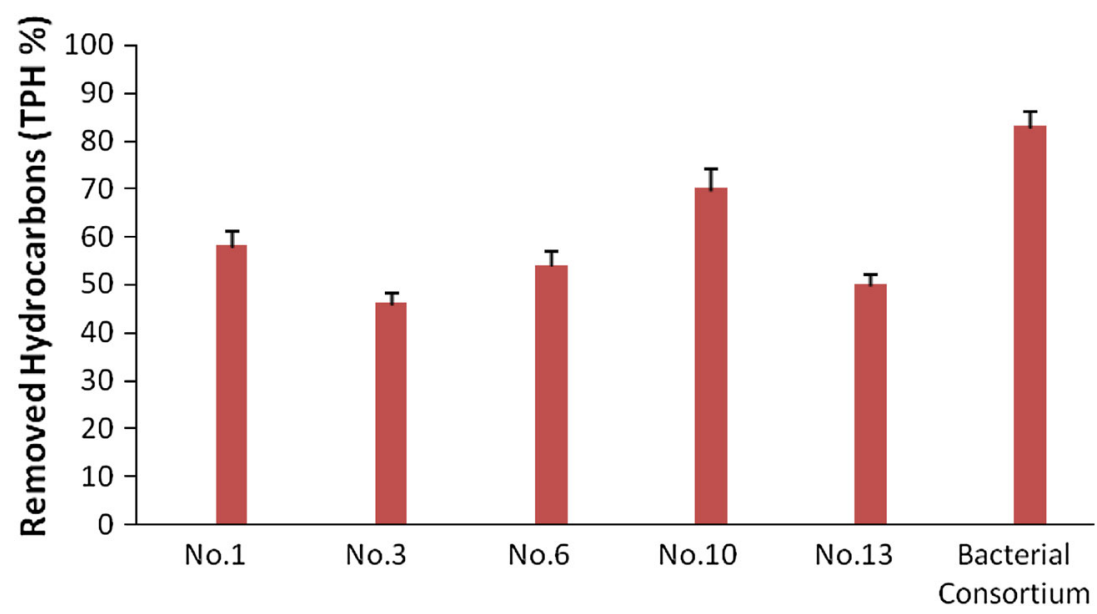

were formed and biodegradation of hydrocarbons significantly improved (Mehta and Kau 2011). For example, by observing the kerosene biodegradation results for strain no. 13 and no. 10, it was found that although both strains identified as Pseudomonas aeruginosa species, the no. 13 biosurfactant was clearly more active in surface tension reduction than emulsification. The surface tension reduction of no. 10 is lower, but it is a stronger emulsifier and since its activity is more balanced, it resulted in a higher biodegradation efficiency.

Application of consortium to bioremediation of the crude oil-contaminated soils

Both the biodegradation results and the biosurfactants activities measurements were used to select appropriate species to form a consortium for fast bioremediation of oilcontaminated soils. The final consortium consisted of strains no. 3, 13, 6, 1 and 10. The first three strains were selected because of their capability to produce effective biosurfactants; the next one was selected for its high efficiency in biodegradation of kerosene hydrocarbons; and the last was a good emulsifier producer. The amounts of hydrocarbons removed from an oil-contaminated soil sample by the consortium in comparison with the single isolates in terms of TPH were measured and represented in Fig. 5. The results revealed that the hydrocarbon removal efficiency of the consortium is much higher than that of single species. The biodegradation efficiency of the strains no. 1 and no. 10 was equal to 58 and $70 \%$, respectively, while the consortium degraded about $83 \%$ of the original hydrocarbon content of the system.
The application of microbial consortia has been considered as an effective option to bioremediation of the hydrocarbon-contaminated sites. In this work, we examine the capability of a tailored bacterial consortium in biodegradation of the hydrocarbon content of an oil-contaminated soil sample. Results indicated that the consortium had a higher efficiency than the single strains which could be explained by two different but complementary reasons. The first reason can be described by the comparison between the lag-phase intervals of the two systems. Figure 6 shows the cells density variations with time for single cells as well as the consortium. Comparison of the dynamics of the single cell and consortium population during their growth on crude oil illustrated that the lagphase time for the consortia is far less than that of the single cells. The reasons for such observation can be explained as the result of either lower mass transfer limitations in the consortium system because of its more effective surfactant components or higher concentrations of the induced enzymes in the system.

Secondly, it should be noted that crude oil contains a complex mixture of various types of hydrocarbons, and the tendency of microorganisms to these components is not the same (Mishra and Singh 2012). It is frequently reported that a single isolate has a high biodegradation rate for only a specific fraction of hydrocarbons (Chen et al. 2011). However, biodegradation of a crude oil contamination by a consortium of microorganisms is advantageous because a variety of hydrocarbons would be affected simultaneously increasing the removal efficiency in a timely manner. Moreover, the cometabolism of the crude oil components in a consortium is another possibility which can enhance 


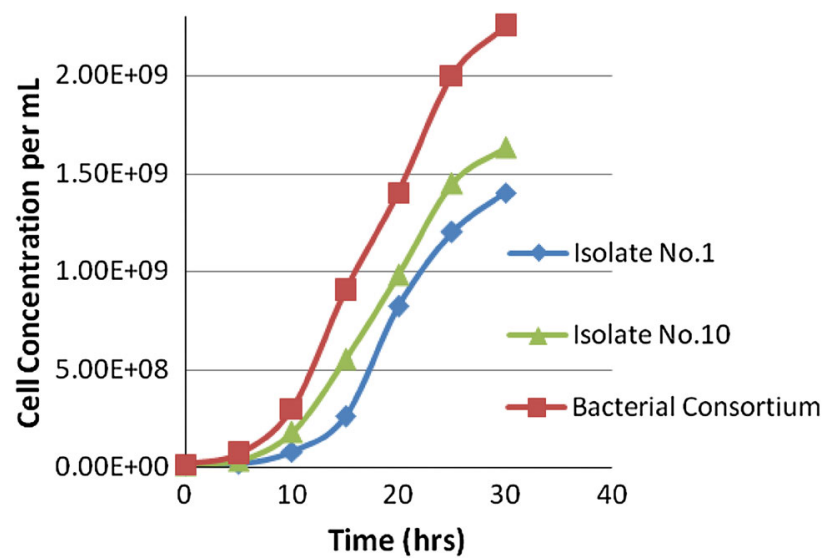

Fig. 6 The cells density variations with time for single cells as well as the consortium

the efficiency and kinetics of biodegradation. It is reported that a number of contributed enzymes in hydrocarbon biodegradation pathways are low specified and can react with more than one specific hydrocarbon substrate. For instance, cooxidation of cyclic hydrocarbons such as cyclohexane during microbial growth on alkanes has been reported by Beam and Perry (1974). In fact, the alkane monooxygenases initially induced by alkanes convert the cyclic compounds to their corresponding cycloalcohols or cycloketones which can be easily degraded by several bacteria such as pseudomonas species. Therefore, it can be said that biodegradation through cometabolism would be triggered by versatile enzymes produced in the consortium which leading to a higher removal efficiency.

Biodegradation rate of petroleum hydrocarbons depends on various parameters including the hydrocarbon composition of the petroleum and the physical and chemical properties of the contaminated site. This variation makes it difficult to define a certain condition for the "fast biodegradation". However, biodegradation of the majority of the hydrocarbons present in a system (TPH) in a short period of time (e.g., $<7$ days) has been considered as fast biodegradation (Binazadeh et al. 2009). Consequently, the consortium of bacteria in this study showed a high potential in fast biodegradation, and its biodegradation rate was higher than many previous reports in similar conditions (Robles-González et al. 2008; Cerqueira et al. 2011; Gojgic-Cvijovic et al. 2012). The reason can be explained by the balanced activity of the surfactant system in the present consortium. In fact, the coexistence of biosurfactants and bioemulsifiers produced by the consortium facilitated the formation of smaller emulsion droplets which in turn provided the bacteria with a larger interfacial area between the two immiscible phases and raised the biodegradation kinetics significantly. Using a mixture of surfactants with different surface active properties to produce stable small size emulsions has been reported in the industrial applications and nano-emulsion formation (Mattei et al. 2014; Izquierdo et al. 2005).

Recently, Cameotra and Singh (2009) observed active pinocytosis of hydrocarbons to cells at the presence of biosurfactants which facilitated the hydrocarbon uptake. They showed that the micro emulsions of hexadecane stabilized by the biosurfactant molecules are internalized directly to the cells which can be considered as an effective mechanism for hydrocarbon transfer to the bacteria. Therefore, the formation of more stable micro emulsions as a result of the complex biosurfactant system produced by the consortia and the resultant active bio uptake mechanism could be considered as the second reason supporting the higher hydrocarbon removal efficiency of the consortia.

\section{Conclusion}

To achieve an effective consortium of bacteria to fast biodegradation of crude oil hydrocarbons, 18 bacteria were isolated from oil-contaminated soil samples and screened for biosurfactant production and hydrocarbons biodegradation. The selected bacteria were identified as Bacillus subtilis and Pseudomonos aeruginosa through 16S-rRNA analysis. Their biosurfactants were partially characterized as lipopeptide and glycolipid compounds which could reduce the surface tension of water for at least $34 \mathrm{mN} / \mathrm{m}$. The selected isolates were applied to a slurry phase bioremediation of a crude oil-contaminated soil sample, and its total petroleum hydrocarbon removal efficiency was compared with that of the most active single species. It was observed that the removal efficiency of the consortium is much higher than single species, and the observation was substantiated by four reasons, namely, more active biosurfactant in the consortium, smaller emulsion droplets in the consortium and active internalization of hydrocarbons to the cells, longer lag phase of the single species system and simultaneous degradation of a variety of hydrocarbons by the consortium. At last, it can be concluded that a 
consortium containing suitable species will actually be very effective in bioremediation of oil-contaminated soils.

Acknowledgments This research was partially supported by Isfahan Oil Refinery Company. The authors gratefully acknowledge the University of Isfahan research office for the financial support.

\section{References}

Abbasnezhad H, Gray MR, Foght JM (2008) Two different mechanisms for adhesion of Gram-negative bacterium, Pseudomonas fluorescens LP6a to an oil-water interface. Colloids Surf B 62:36-41

Abouseoud M, Maachi R, Amrane A, Boudergua S, Nabi A (2008) Evaluation of different carbon and nitrogen sources in production of biosurfactant by Pseudomonas fluoresens. Desalination 223:143-151

Beam HW, Perry JJ (1974) Microbial degradation of cycloparaffinic hydrocarbons via co-metabolism and commensalism. J Gen Microbiol 8:163-169

Binazadeh M, Karimi IA, Li Z (2009) Fast biodegradation of long chain n-alkanes and crude oil at high concentrations with Rhodococcus sp. Moj-3449. Enzyme Microb Technol 45:195-202

Biria D, Maghsoudi E, Roostaazad R (2013) Application of power law logistic model to growth kinetics of Bacillus licheniformis MS3 on a water insoluble substrate. Chem Eng Commun. doi:10. 1080/00986445.2013.819351

Bordoloi NK, Konwar BK (2009) Bacterial biosurfactant in enhancing solubility and metabolism of petroleum hydrocarbons. J Hazard Mater 170:495-505

Calvo C, Manzanera M, Silva-Castro GA, Uad I, González-López J (2009) Application of bioemulsifiers in soil oil bioremediation processes future prospects. Sci Total Environ 407:3634-3640

Cameotra SS, Singh P (2009) Synthesis of rhamnolipid biosurfactant and mode of hexadecane uptake by Pseudomonas species. Microb Cell Fact 8:16. doi:10.1186/1475-2859-8-16

Cerqueira VS, Hollenbach EB, Maboni F, Vainstein MH, Camargo FAO, Peralba MCR, Bento FM (2011) Biodegradation potential of oily sludge by pure and mixed bacterial cultures. Bioresour Technol 102:11003-11010

Chen J, Yang Q, Huang T, Zhang Y, Ding R (2011) Enhanced bioremediation of soil contaminated with viscous oil through microbial consortium construction and ultraviolet mutation. World J Microbiol Biotechnol 27:1381-1389

Das N, Chandran P (2011) Microbial degradation of petroleum hydrocarbon contaminants: an overview. Biotechnol Res Int. doi: $10.4061 / 2011 / 941810$

Dubois M, Gills KA, Hamilton JK, Rebers PA, Smith F (1956) Colorimetric method for determination of sugar and related substances. Anal Chem 28:350-356

Ghazali FM, Abdul-Rahman RNZ, Salleh A, Basri M (2004) Biodegradation of hydrocarbons in soil by microbial consortium. Int Biodeterior Biodegradation 54:61-67

Gojgic-Cvijovic GD, Milic JS, Solevic TM, Beskoski VP, Ilic MV, Djokic LS, Narancic TM, Vrvic MM (2012) Biodegradation of petroleum sludge and petroleum polluted soil by a bacterial consortium: a laboratory study. Biodegradation 23:1-14
Izquierdo P, Feng J, Esquena J, Tadros TF, Dederen JC, Garcia MJ, Azemar N, Solans C (2005) The influence of surfactant mixing ratio on nano-emulsion formation by the pit method. J Colloid Interface Sci 285:388-394

Ko KS, Oh WS, Lee MY et al (2006) Bacillus infantis sp. nov. and Bacillus idriensis sp. nov., isolated from a patient with neonatal sepsis. Int J Syst Evol Microbiol 56:2541-2544

Kumar A, Bisht BS, Joshi VD, Dhewa T (2011) Review on bioremediation of polluted environment: a management tool. Int J Environ Sci 1:1079-1093

Lowry OH, Rosebrough NJ, Farr AL, Randall RJ (1951) Protein measurement with the Folin phenol reagent. J Biol Chem 193:265-275

Makkar RS, Rockne KJ (2003) Comparison of synthetic surfactants and biosurfactants in enhancing biodegradation of polycyclic aromatic hydrocarbons. Environ Toxicol Chem 22:2280-2292

Mattei M, Kontogeorgis GM, Gani R (2014) A comprehensive framework for surfactant selection and design for emulsion based chemical product design. Fluid Phase Equilib 362:288-299

Mbadinga SM, Wang LY, Zhou L, Liu JF, Gu JD, Mu BZ (2011) Microbial communities involved in anaerobic degradation of alkanes. Int Biodeterior Biodegradation 65:1-13

Mehta SK, Kau G (2011) Microemulsions: thermodynamic and dynamic properties 381. In: Mizutani T (ed) Thermodynamics, 1 st edn. InTech, Winchester, pp 381-407

Mishra S, Singh SN (2012) Microbial degradation of $n$-hexadecane in mineral salt medium as mediated by degradative enzymes. Bioresour Technol 111:148-154

Mukherjee S, Das P, Sen R (2006) Towards commercial production of microbial surfactants. Trends Biotechnol 24:509-515

Mulligan CN, Yong RN, Gibbs BF (2001) Surfactant enhanced remediation of contaminated soil. Eng Geol 60:371-380

Noha HY, Duncana KE, Naglea DP, Savagea KN, Knapp RM, McInerney MJ (2004) Comparison of methods to detect biosurfactant production by diverse microorganisms. J Microbiol Methods 56:339-347

Palittapongarnpim M, Upatham PP, Tangbanluekal ESL (1998) Biodegradation of crude oil by soil microorganisms in the tropic. Biodegradation 9:83-90

Rahman KSM, Thahira-Rahman J, Lakshmanaperumalsamy P, Bana IM (2002) Towards efficient crude oil degradation by a mixed bacterial consortium. Bioresour Technol 85:257-261

Rayu S, Karpouzas DG, Singh BK (2012) Emerging technologies in bioremediation: constraints and opportunities. Biodegradation 23:917-926

Robles-González IV, Fava F, Poggi-Varaldo HM (2008) A review on slurry bioreactors for bioremediation of soils and sediments. Microb Cell Fact 7:5-23

Ron EZ, Rosenberg E (2002) Biosurfactants and oil bioremediation. Curr Opin Biotechnol 13:249-252

Ruggeri C, Franzetti A, Bestetti G, Caredda P, La Colla P, Pintus M, Sergi S, Tamburini E (2009) Isolation and characterisation of surface active compound-producing bacteria from hydrocarboncontaminated environments. Int Biodeterior Biodegradation 63:936-942

Soberón-Chávez G, Lépine F, Déziel E (2005) Production of rhamnolipids by Pseudomonas aeruginosa. Appl Microbiol Biotechnol 68:718-725

Vasconcellos SP, Crespim E, Cruz GF, Senatore DB, Simioni KCM, Neto EVS, Marsaioli AJ, Oliveira VM (2009) Isolation, 
biodegradation ability and molecular detection of hydrocarbon degrading bacteria in petroleum samples from a Brazilian offshore basin. Org Geochem 40:574-588
Watanabe K (2001) Microorganisms relevant to bioremediation. Curr Opin Biotechnol 12:237-241 